\title{
MRS On-Site Program Offers Over 40 Short Courses, Completes Joint Venture
}

Over 40 short courses, varying in length from one to three days, are now available from the Materials Research Society for presentation at the site of a requesting organization. During the past two years the MRS Short Course Program has grown significantly, and is now widely recognized for its unique form of quality education for scientists, engineers, managers, and technical personnel working in a diverse range of materials-related disciplines.

The year 1988 marked the first year that the Materials Research Society has presented short courses at technical meetings sponsored by other professional organizations. In February MRS presented four short courses on the weekend preceding the World Congress on Superconductivity in Houston, Texas. Four short courses from the MRS portfolio were modified to emphasize high temperature supercon- ductivity themes: Sol-Gel Processing (Instructor-C. Jeffrey Brinker, Sandia National Laboratories); Film and Coating Deposition Techniques (Instructor-Donald M. Mattox, Sandia National Laboratories); Film Formation and Characterization (Instructor-Donald M. Mattox); and Superconductive Materials and Applications (Instructor-Robert E. Schwall, IBM Visiting Scientist at MIT). The program was well received by the participants and proved to be a successful collaboration in education. Other joint educational ventures with professional societies are planned.

The MRS portfolio of short courses for on-site presentation is specifically designed as training for research professionals in current and emerging areas of materials science. Emphasis is given to areas where written information may not be widely available and the direct experience of the instructor is invaluable. The MRS Short Course Program provides: up-todate specialty and review courses, technology transfer and problem solving, contact with outstanding experts in their fields, course content tailored to the needs of attendees, and cost-effective education.

MRS On-Site courses can be purchased by a requesting organization for a fixed fee. Up to 30 attendees can be placed in a course, and there are no travel costs for staff and minimal time is lost from work.

An On-Site Short Course portfolio with detailed descriptions and topical outlines for each course is available from the MRS Short Course Manager, Vivienne Harwood Mattox (505) 294-9532.

Vivienne Harwood Mattox MRS Short Course Manager

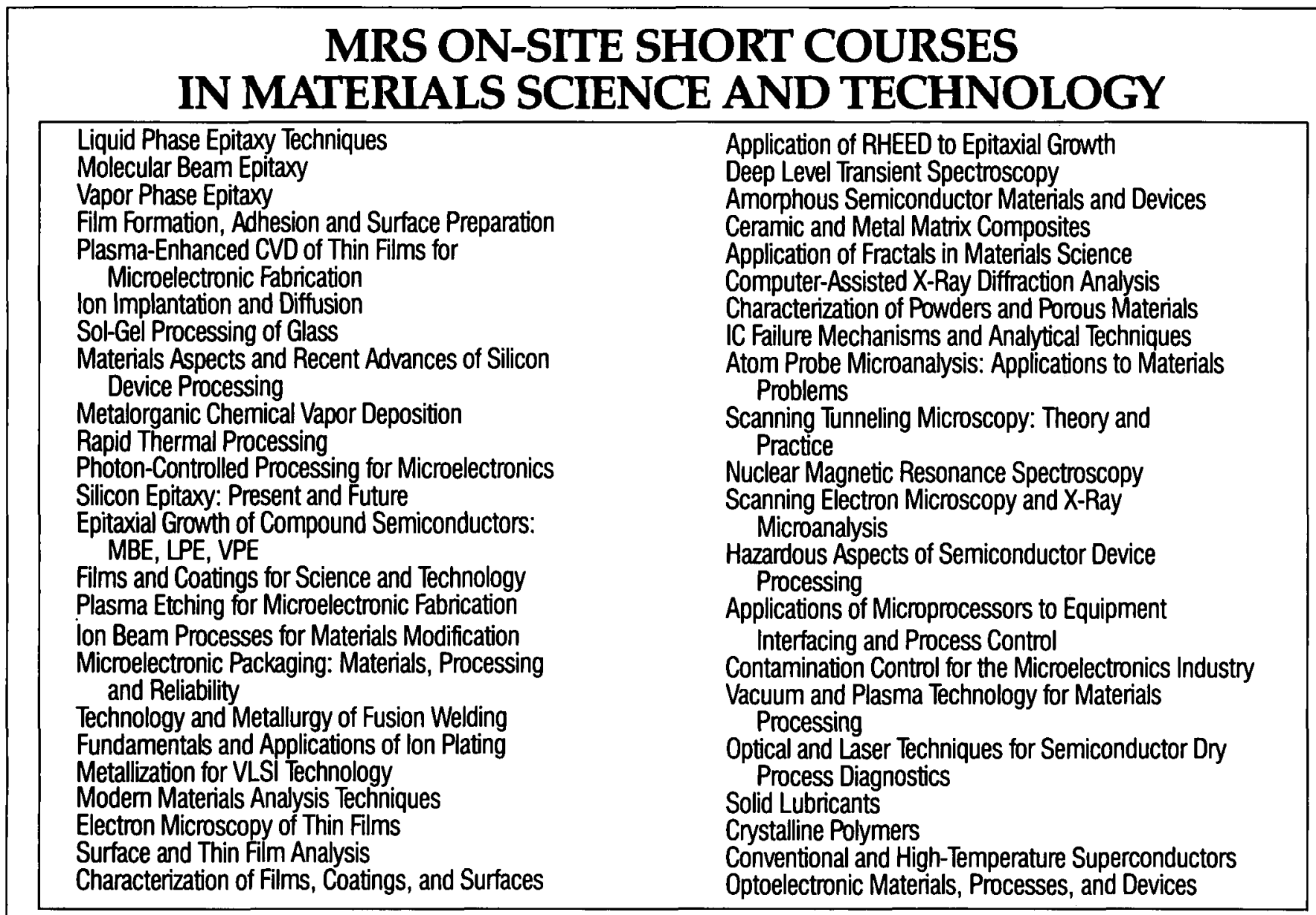

For details about MRS On-Site Short Courses, contact Vivienne Hanwood Mattox (505) 294-9532. 